\title{
Thermal Analyses of Power Electronics Integrated with Vapour Chamber Cooling
}

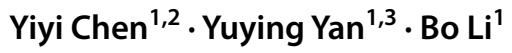

Received: 28 March 2020 / Accepted: 3 October 2020 / Published online: 18 November 2020

(c) The Author(s) 2020

\begin{abstract}
Insulated gate bipolar transistor (IGBT) power module is used for power switching transistor devices in the power supply and motor control circuits in both hybrid electric vehicles and electric vehicles. The target of heat flux of IGBT is continuously increasing due to the demand for power rating improvements and miniaturisation. Without suitable efficient cooling technologies, excessively high temperature and uneven temperature distribution can cause high thermal stress, eventually leading to severe module failures. Therefore, highly efficient cooling solutions are highly required. Vapour chamber with phase change can provide quick heat transfer and low temperature gradient. This study proposes a new IGBT structure integrated with vapour chamber. The tests and simulation results indicate that the thermal and thermo-mechanical performances of IGBT integrated with vapour chamber are better than those of the IGBT with copper baseplate module. The thermal resistance between the junction and heat sink is reduced from 0.25 to $0.14{ }^{\circ} \mathrm{C} / \mathrm{W}$, and the temperature uniformity is greatly improved due to the phase change in the vapour chamber. The simulation also investigates the thermal stress distribution, deformation and thermal fatigue lifespan of IGBT power electronics module. A reduction of $21.8 \%$ in thermal stress and an increase of 9\% in lifespan of $\mathrm{Sn}-3.5 \mathrm{Ag}$ solder are achieved.
\end{abstract}

Keywords Power electronics $\cdot$ IGBT $\cdot$ Phase change cooling $\cdot$ Thermal performances $\cdot$ Thermal fatigue lifespan

\section{Abbreviations \\ DBC Direct bonded copper \\ EV Electric vehicle \\ HEV Hybrid electric vehicle \\ IGBT Insulated gate bipolar transistor}

\section{Introduction}

From the viewpoint of protecting the global environment, the reduction of carbon dioxide emissions has been required. Hybrid electric vehicles (HEVs) and electric vehicles (EVs) tend to have lower carbon dioxide emissions. The insulated gate bipolar transistor (IGBT) power electronics in the

Yuying Yan

yuying.yan@nottingham.ac.uk

1 Faculty of Engineering, University of Nottingham, Nottingham NG7 2RD, UK

2 Dynex Semiconductor Limited, Doddington Road, Lincoln LN6 3LF, UK

3 Research Centre for Fluids and Thermal Engineering, University of Nottingham, Ningbo 315100, China inverter is used to distribute and convert the direct current from battery to alternating current [1]. It also switches with high speed for satisfying the current frequency requirement. Therefore, the IGBT power electronics module is considered as the heart of the electric drivetrain.

\subsection{Thermal Challenges of IGBT Modules in EVs and HEVs}

IGBT modules must operate stably during the whole vehicle's lifespan to maintain a safe condition in EVs and HEVs. The loss from IGBT module is in the form of heat energy during normal switching operation, which has the possibility to cause power electronics faults. The heat flux of IGBT modules tends to increase greatly due to more functionality and minimised die feature size. Therefore, the demand for an efficient cooling solution is crucial in developing advanced IGBT modules for EVs and HEVs.

The thermal challenges of IGBT modules in automotive area are summarised in Table 1. It can be found that the heat dissipation density will inevitably increase and operation conditions become increasingly harsh [2]. 
Table 1 Thermal challenges for power semiconductors [2]

\begin{tabular}{ll}
\hline Trends & Effects \\
\hline Placement under bonnet or on engine & Increasing ambient operating temperature \\
Highly integrated components & Higher power losses \\
Increasing voltage and current capability & Higher power losses \\
Electrically isolated baseplate & More difficult to cool power devices \\
Increasing switching speeds & Higher heat fluxes \\
Miniaturisation & Higher heat dissipation density \\
\hline
\end{tabular}

Table 2 Potential failures of IGBT power module [4]

\begin{tabular}{|c|c|c|c|c|}
\hline Failure sites & Causes & Stresses & Modes & Mechanisms \\
\hline Bond pad & High temperature & Thermal overstress & Open circuit & Metallisation reconstruction \\
\hline Bonding wire & $\begin{array}{l}\text { Coefficient of thermal expansion } \\
\text { mismatch, high temperature }\end{array}$ & Thermo-mechanical stress & Bond wire lift off, heel crack & Fatigue \\
\hline Solder joint & $\begin{array}{l}\text { Coefficient of thermal expansion } \\
\text { mismatch, transformation in } \\
\text { solder microstructure at high } \\
\text { temperature }\end{array}$ & Thermo-mechanical stress & Solder joint cracks & Fatigue or grain growth \\
\hline Ceramic substrate & Thermal shock & Thermo-mechanical stress & delamination & Delamination of metallisation \\
\hline
\end{tabular}

\subsection{IGBT Power Electronics Module Failure Mechanisms}

The thermal fatigue lifespan of the IGBT module is determined by failure mechanisms related to thermal stress. Thermal stress generates when the IGBT module operates; therefore, the bonded surfaces, solder layer and wire bonding are continually affected. In the IGBT modules, solder joint cracking, delamination of direct bonded copper (DBC), heel cracks and bonding wire lift-off are the main failure modes. With the number of failures increasing, the thermal deformation and cracks result in high thermal resistance of the module. The increased thermal resistance further leads to high operating temperature, which brings about high thermal stress and eventually accelerates the module failure [3]. Qian et al. [4] summarised the potential failures of the IGBT power module as shown in Table 2. Fatigue is the most reported failure resulting from overheating. Therefore, it is urgent to improve the thermal management to achieve long-term reliability.

$\mathrm{Sn}-3.5 \mathrm{Ag}$ solder layer is used for joining the chip and DBC layer, and the DBC layer and substrate. Melting temperatures of solders are low, and the deformation of solder is highly dependent on the temperature and strain rate [5]. With increases in temperature and thermal stress, delamination and cracking of the solder will be promoted, leading to thermal resistance increase and junction temperature growth, therefore accelerating module failures.

When the IGBT module operates, wire-bonding suffers from large temperature fluctuation due to heat dissipation
Table 3 Typical values of the convection heat transfer. Source: Bergman, T.L., et al. Fundamentals of heat and mass transfer. 2011

\begin{tabular}{ll}
\hline Cooling solutions & $\begin{array}{l}\text { Heat transfer } \\
\text { coefficient }[(\mathrm{W} / \\
\left.\left.\mathrm{m}^{2} \cdot \mathrm{K}\right)\right]\end{array}$ \\
\hline $\begin{array}{l}\text { Free convection by gas } \\
\text { Forced convection by gas }\end{array}$ & $2-25$ \\
Free convection by water & $25-250$ \\
Forced convection by water & $50-1,000$ \\
Convection with phase change & $100-20,000$ \\
\hline
\end{tabular}

in the silicon and the wire. Generally, the bonded wire failure takes place predominantly due to shear stresses generated between the bond pad and the wire bonding. Eventually, the wires lift off or suffer from heel crack propagation.

Thermal fatigue lifespan of the substrate depends on the growth of a fatigue crack in copper from a geometric singularity and close to the interface between upper copper and ceramic layer. The crack bifurcates and breaks the ceramic layer when it reaches critical condition.

\subsection{Cooling Solutions}

There are a number of methods to cool power electronics in different applications. Large variation exists in complexity, cost, cooling capacity, weight, lifespan and reliability of major cooling methods. Table 3 shows the thermal performances for various cooling methods and their typical range of heat transfer coefficients [6]. The convective heat 
transfer coefficient depends on physical properties of fluid and physical situations such as contact surface geometry, the properties of walls, bulk fluid velocity and nature of fluid motion. The highest heat transfer coefficients of boiling heat transfer range from 2500 to $100,000 \mathrm{~W} /\left(\mathrm{m}^{2} \cdot \mathrm{K}\right)$. Boiling heat transfer dissipates large amounts of heat from heat source by the transport of latent heat, which is suitable for electronics devices with high heat dissipation rate.

Among the cooling methods used in power electronics modules presented in Table 3, the air cooling solution is difficult to meet the cooling demand that the power dissipation exceeds $1500 \mathrm{~W}$ due to many physical and design constraints although it has sufficed for many lower power electronic devices [7]. Micro-channel liquid cooling solutions are attracted attentions over the past decade due to high cooling capacity, compactness and lightweight. Yin et al. [8] and Stevanovic et al. [9] developed a compact structure that micro-channels are directly fabricated on DBC. Singh et al. [10] fabricated a copper-based micro-channel heat sink for power electronics cooling. It can remove more than 4.1 MW/ $\mathrm{m}^{2}$ heat flux and keep the temperature below $100 \pm 5^{\circ} \mathrm{C}$. However, micro-channel cooling solutions strongly consume the pump power to improve the cooling capacity. Besides, low temperature uniformity is a main issue in micro-channel cooling system. Jet impingement cooling systems have been explored in microelectronics due to its high flow rate with lower pumping power and high local heat transfer rate. $\mathrm{Wu}$ et al. [11] developed a jet impingement cooling structure for power electronics application, which provided sufficient cooling to the top and side surfaces of the chip. The experimental results showed the total thermal resistance could be as low as $0.041 \mathrm{~K} / \mathrm{W}$ at a low flow rate of $1800 \mathrm{~mL} / \mathrm{min}$. Whelan et al. [12] investigated the effects of nozzle geometry in liquid jet array impingement. Six different nozzle geometries were evaluated. It was found that the confined submerged and free-surface scenarios yield greater heat transfer coefficients for a given hydraulic pumping power. Chamfering and contouring inlet nozzle configurations reduced in pressure drop. Agbim et al. [13] carried out simulations and tests about an array impingement cooling system. It was found that the difference in heat transfer coefficient for the aligned and staggered jet array configuration is minimal. However, temperature field was non-uniform because heat removal capacity rapidly degrades when it was away from the centre of the jet region [14]. Besides, the applicability of jet impingement cooling structure is restricted by uneconomic, complex cooling structure, coolant leakage and blockage. Therefore, a cost-saving but more reliable thermal management device is required. Phase-change cooling strategies become more attractive for higher thermal demands. Due to the drawbacks of the traditional cooling strategies mentioned above, vapour chamber as a super-heat-conductive device gradually becomes an appealing option for cooling component. It utilises a phase-change heat transfer process to spread heat evenly and eliminate hot spots across IGBT module. Vapour chambers heat sinks are smaller and lighter than other traditional heat sinks. Moreover, no external means of energy is required to complete phase change process. Based on Connors [15], a vapour chamber was embedded on IGBT module. The heat spread much more evenly across the entire heat sink, which leads to a drop in overall thermal resistance of $12 \%$.

An IGBT integrated with vapour chamber module is studied here. Elastic-plastic-creep analysis model is employed to simulate the mechanical property of $\mathrm{Sn}-3.5 \mathrm{Ag}$ solder layer under power cycling. The inelastic energy density is used to predict the thermal fatigue lifespan. Besides, an experiment is conducted to measure the thermal resistance and temperature uniformity of the module.

\section{Cooling Strategy Design for IGBT Power Electronics}

In a convectional IGBT module, thermal grease is employed for decreasing the contact thermal resistance between copper baseplate and a heat sink. In direct cooling structure, the baseplate and heat sink are integrated into one and the coolant directly contacts the baseplate. Therefore, the thermal grease and additional cooling heat sink are eliminated. As shown in Fig. 1, the thermal resistance is reduced by $33 \%$ [16].

The new IGBT module cooling structure is presented in Fig. 2. Compared by the convection structure of IGBT module, it is designed for reducing the thermal resistance. The indirect liquid cooling is changed to the direct cooling structure. Thermal grease is removed, and the copper baseplate is replaced by vapour chamber baseplate.

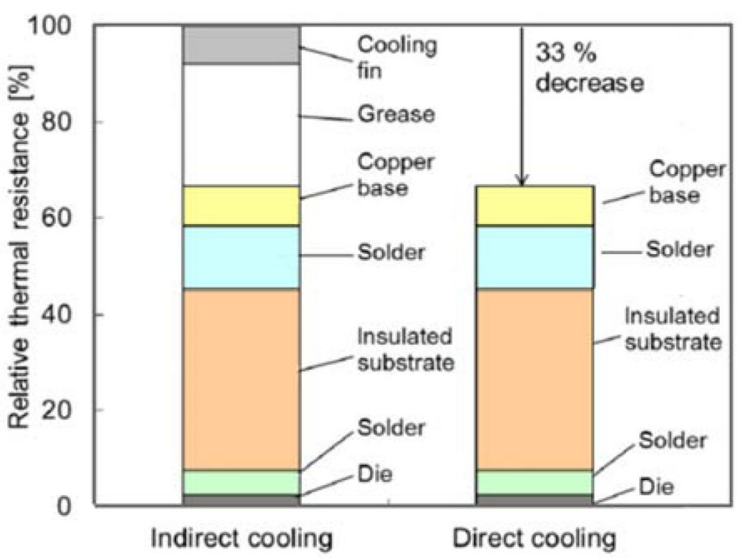

Fig. 1 Comparison in thermal resistance between indirect cooling and direct cooling of IGBT module 


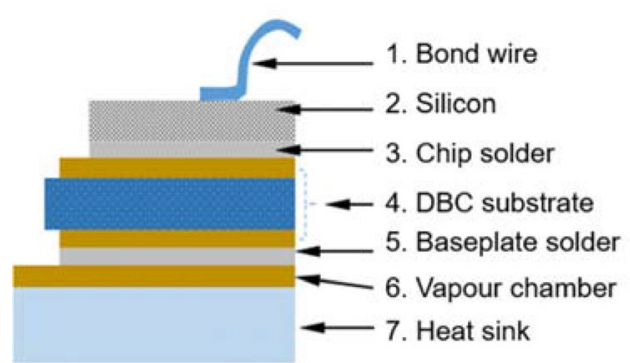

Fig. 2 IGBT power electronics module integrated with vapour chamber

\section{Simulation and Test Set-up}

A coupling thermo-mechanical model and a thermal fatigue model are established with finite element method to investigate thermo-mechanical performance of solder layer and estimate lifespan. Also, an experiment is built to test thermal performances of vapour chamber direct cooling and conventional copper direct cooling of an IGBT power module. The experiment mainly investigated the thermal resistance and temperature uniformity.

\subsection{Simulation}

The simulations are conducted to investigate solder thermal performance and reliability. Thermal stress and deformation are evaluated to investigate crack imitation and propagation. Energy density as the failure parameter is used to predict the lifespan of chip solder layer.

\subsubsection{Module Description}

The module is composed of six pairs of IGBT chips, diodes, solders, substrate and baseplate. The substrate layer consists of an aluminium oxidation layer $\left(\mathrm{Al}_{2} \mathrm{O}_{3}\right)$ sandwiched by two copper layers. $\mathrm{Sn}-3.5 \mathrm{Ag}$ and $\mathrm{Sn}-\mathrm{Pb}$ materials are used as solder joints for chips/diodes and baseplate, respectively. The material physical properties and sizes of components are listed in Tables 4 and 5.
Table 5 Component sizes in simulation model

\begin{tabular}{llll}
\hline Component & \multicolumn{3}{l}{ Dimensions $(\mathrm{mm})$} \\
\cline { 2 - 4 } & Length & Width & Depth \\
\hline Silicon chips & 9.718 & 3.342 & 0.020 \\
Silicon diode & 11.146 & 7.746 & 0.020 \\
DBC copper layer & 47.140 & 44.350 & 0.300 \\
DBC aluminium oxidation & 48.740 & 46.480 & 0.635 \\
Baseplate & 122 & 62 & 5 \\
\hline
\end{tabular}

\subsubsection{Material Models}

Elastic-plastic-creep model is used to simulate the thermomechanical property of the $\mathrm{Sn}-3.5 \mathrm{Ag}$ solder layer. Garofalo hyperbolic sine law is applied to the solder layer.

$\frac{\mathrm{d} \varepsilon}{\mathrm{d} t}=A[(\sin h) \cdot B \sigma]^{n} \mathrm{e}^{\left(\frac{\Delta Q}{R_{\mathrm{g}} T}\right)}$

The $\varepsilon^{\mathrm{cr}}$ is the equivalent uniaxial creep strain; $\sigma$ is the equivalent tensile stress; $T$ is absolute temperature; $R_{\mathrm{g}}$ is the gas constant $\left[R_{\mathrm{g}}=8.314 \mathrm{~J} /(\mathrm{mol} \cdot \mathrm{K})\right] ; A$ is creep rate coefficient $\left(A=44,100 \mathrm{~s}^{-1}\right) ; B$ is the reciprocal of effective stress $\left(B=0.005 \mathrm{MPa}^{-1}\right) ; n$ is Garofalo parameter $(n=4.2) ; \Delta Q$ is activation energy $(\Delta Q=44,995 \mathrm{~J} / \mathrm{mol})$ [17]. Morrow energy-based fatigue model is employed to predict lifespan of $\mathrm{Sn}-3.5 \mathrm{Ag}$ solder layer. The inelastic energy density including creep and plastic is applied to the Morrow fatigue model.

$\Delta W_{\text {in }}=W_{\mathrm{f}}^{\prime}\left(2 N_{\mathrm{f}}\right)^{m}$

Where $\Delta W_{\text {in }}$ is inelastic strain energy density; $W_{\mathrm{f}}^{\prime}$ is fatigue energy coefficient; $N_{\mathrm{f}}$ is fatigue cycles; $m$ is fatigue energy exponent with value of -0.69 .

\subsubsection{Boundary Conditions}

Power losses consist of steady-state conduction losses and switching loss in IGBT power electronics module. In total, each IGBT chip and diode generate $96.83 \mathrm{~W}$ and $26.17 \mathrm{~W}$ of power loss, respectively. Xu et al. [18] stated that diodes cycle is six times shorter than IGBT cycle. In this simulation, IGBT cycle is set to $60 \mathrm{~min}$ and diode cycle is set to $10 \mathrm{~min}$ as shown in Fig. 3. The boundary conditions applied in the simulation are provided in Table 6.
Table 4 IGBT material physical properties

\begin{tabular}{llllllll}
\hline & $\mathrm{Al}_{2} \mathrm{O}_{3}$ & $\mathrm{Cu}$ & Vapour chamber & $\mathrm{Al}$ & $\mathrm{Si}$ & $\mathrm{Sn}-3.5 \mathrm{Ag}$ & $\mathrm{Sn}-\mathrm{Pb}$ \\
\hline Thermal capacity $[\mathrm{J} /(\mathrm{kg} \cdot \mathrm{K})]$ & 730 & 320 & 385 & 904 & 678 & 240 & 242 \\
Thermal conductivity $[\mathrm{W} /(\mathrm{m} \cdot \mathrm{K})]$ & 35 & 413 & 5000 & 237 & 71 & 52 & 57 \\
Coefficient of thermal expansion $\left[10^{-6} / \mathrm{K}\right]$ & 6.5 & 17 & 17 & 23.1 & 2.1 & 25 & 19 \\
\hline
\end{tabular}




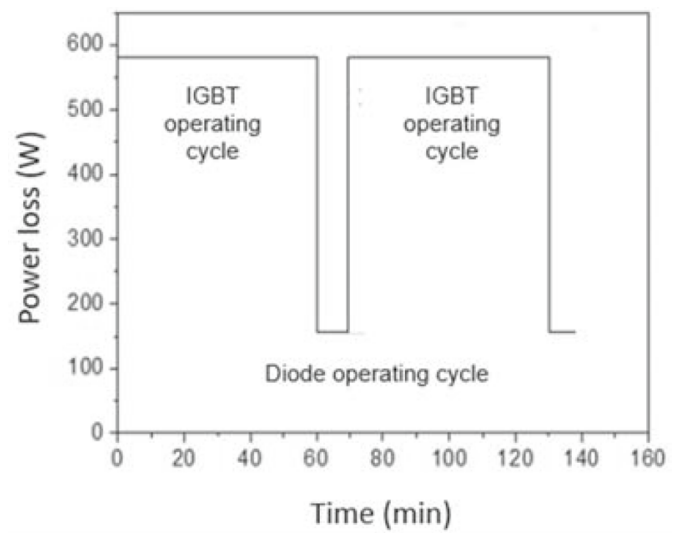

Fig. 3 IGBT power loss cycle

Table 6 Boundary condition in IGBT modelling

\begin{tabular}{ll}
\hline Initial module temperature & $20{ }^{\circ} \mathrm{C}$ \\
Power applied to each diode & $26.17 \mathrm{~W}$ \\
Power applied to each IGBT chip & $96.83 \mathrm{~W}$ \\
Ambient temperature & $20{ }^{\circ} \mathrm{C}$ \\
Heat sink temperature & $75{ }^{\circ} \mathrm{C}$ \\
Air-free convection coefficient & $5 \mathrm{~W} / \mathrm{m} \cdot \mathrm{K}$ \\
\hline
\end{tabular}

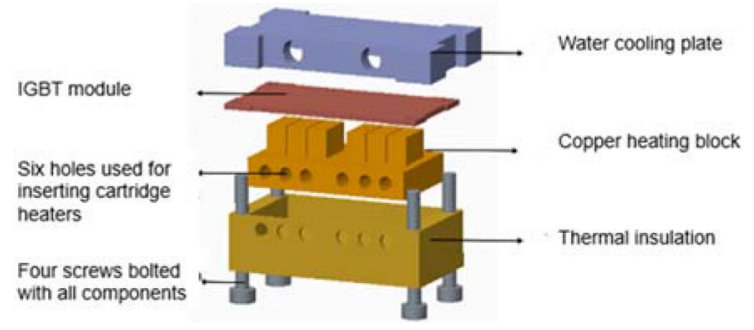

Fig. 4 Schematic diagram of the IGBT power module with the heat sink and heat source

In mechanical boundary conditions, the baseplate of IGBT module and four bolt holes are fixed in all directions, while other layers deform freely to all directions.

\subsection{Test Set-up and Verification}

The schematic diagram of the IGBT power model with the heat sink and heat source is shown in Fig. 4. Copper heating block with cartridge heaters is in contact with the IGBT chips and diodes to supply heat input. Thermal grease TIG780-38 with thermal conductivity of $3.8 \mathrm{~W} /(\mathrm{m} \cdot \mathrm{K})$ is introduced between heater block and IGBT chips/diodes to reduce contact thermal resistance. The baseplate of IGBT module is directly cooled by cooling water supplied by a water bath (Polyscience). T-type thermocouples are placed
Table 7 Comparison of junction temperature for validation

\begin{tabular}{llll}
\hline Junction temperature & Chip 1 & Chip 2 & Chip 3 \\
\hline Temperature from simulation $\left({ }^{\circ} \mathrm{C}\right)$ & 106.1 & 109.3 & 105.5 \\
Temperature from test $\left({ }^{\circ} \mathrm{C}\right)$ & 98.2 & 98.2 & 97.9 \\
\hline
\end{tabular}

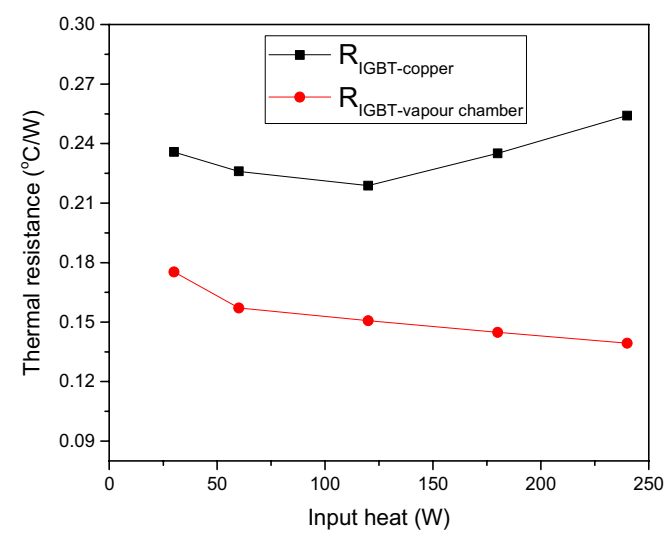

Fig. 5 Thermal resistance of IGBT power module

on IGBT module and water cooling plate to measure temperature. Temperature data are recorded by a date acquisition system (DataTaker DT800). The IGBT module and heat sink are enclosed into a polyurethane container to minimise the heat loss.

The simulation is validated by comparing junction temperature obtained from experiment results during IGBT operating cycle shown in Fig. 3. There are three junction temperature measured on three chips. Table 7 shows the junction temperature of chip 1 , chip 2 and chip 3 . The experiment results are close to the simulation results, and the average error is $8.27 \%$.

\section{Results and Discussion}

\subsection{Thermal Resistance and Temperature Uniformity}

Figure 5 shows thermal resistance between junction and heat sink under different heat loads. The thermal resistance of IGBT with copper baseplate is ranged between 0.22 and $0.26{ }^{\circ} \mathrm{C} / \mathrm{W}$ as the heat input from 30 to $240 \mathrm{~W}$. The thermal resistance of IGBT with vapour chamber continuously decreases from 0.18 to $0.14{ }^{\circ} \mathrm{C} / \mathrm{W}$ when heat input ranges between 30 and $240 \mathrm{~W}$, which is attributed to water film recession with the increase in heat input. When the heat input is low, the water film in the vapour chamber should be thick due to the limited phase change, which leads to high evaporation and condensation thermal resistance. Compared 
with IGBT with copper module, IGBTs with vapour chamber modules reduce $45.2 \%$ of junction to ambient thermal resistance at heat input of $240 \mathrm{~W}$.

Non-uniform temperature gradients within material layers can introduce differential thermal strain and lead to further cracking. As shown in Fig. 6, the use of the vapour chamber leads to a much better temperature uniformity than that of copper baseplate. This is because that nucleate boiling occurs when heat is applied to vapour chamber and then heat transfer is enhanced. The temperature difference of copper and vapour chamber baseplate is 5.5 and $1.3{ }^{\circ} \mathrm{C}$, respectively, at heat input of $240 \mathrm{~W}$.

\subsection{Thermo-Mechanical Performance}

In an IGBT module, materials have different thermal expansion coefficients, which generates thermal stress under power cycling. High thermal stress can cause module failures such as delamination of die attach, bonded wire cracking and lift-off. The thermal stress distribution on IGBT module is shown in Fig 7. The highest stress is located in DBC substrate, which is attributed to large mismatch in thermal expansion coefficients between copper and $\mathrm{Al}_{2} \mathrm{O}_{3}$ ceramic material. The high thermos-mechanical stress can lead to the degradation of the solder interface, such as crack, delamination and voids. It is also found that the edge of the interface between upper copper and ceramic layer experiences maximal stress. This indicates that the crack or delamination could start from the edge of this interface. Thermal fatigue increases the thermal impedance. Consequently, the junction temperature further increases and accelerates other failure modes. Additionally, more hot spots and thermal runaway could induce. It is found in Fig. 7 that IGBT with vapour chamber and copper baseplate modules suffers the maximal stresses of 233 and $298 \mathrm{MPa}$, respectively. A reduction of

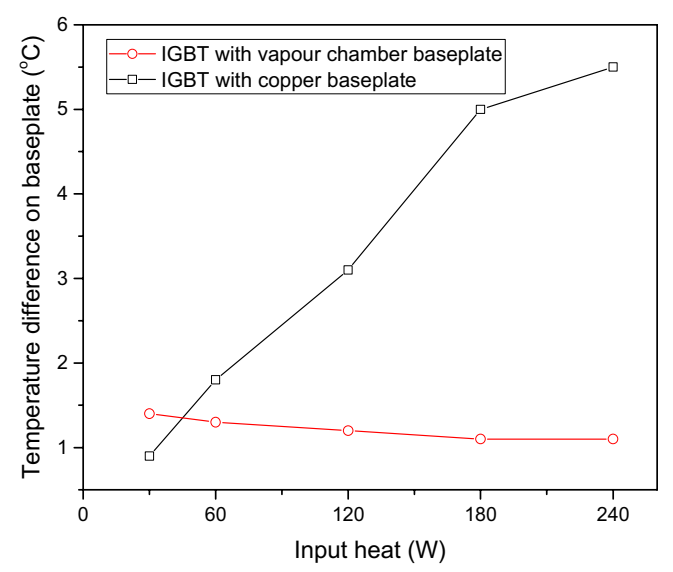

Fig. 6 Temperature difference of copper and vapour chamber baseplate

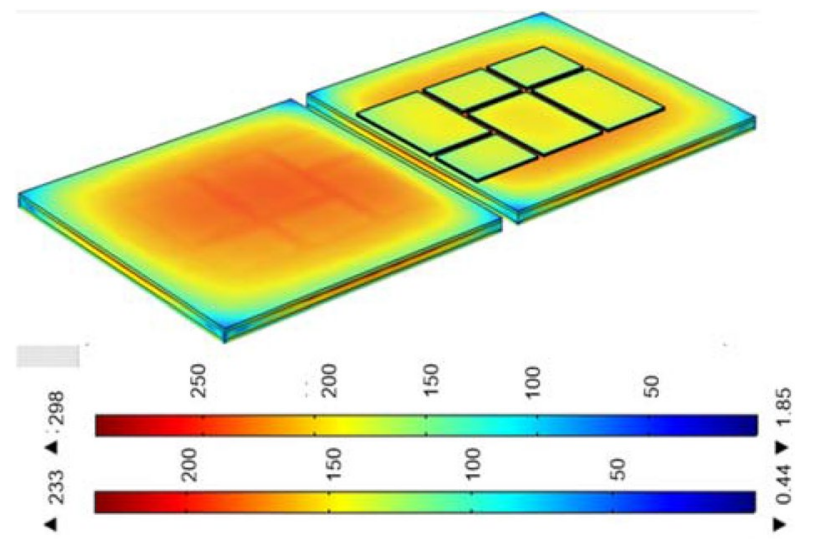

Top bar: IGBT with copper baseplate (MPa) Bottom bar: IGBT with vapour chamber baseplate (MPa)

Fig. 7 Von Mises stress distribution in IGBT module

$21.8 \%$ in thermal stress is achieved. $\mathrm{Sn}-3.5 \mathrm{Ag}$ solder is easily damaged in IGBT module due to its low melting temperature and yield stress and high thermal expansion coefficient.

Figure 8 shows the thermal displacement and deformation shape of $\mathrm{Sn}-3.5 \mathrm{Ag}$ solder layer [19]. Three solder layers bend into a convex shape because of tensile stress and that the upper surfaces displace more than the bottom surfaces. The IGBT with vapour chamber module has a lower maximum displacement of $8.21 \mu \mathrm{m}$ than IGBT with copper baseplate.

Lifespan of the $\mathrm{Sn}-3.5 \mathrm{Ag}$ solder is predicted by using Morrow fatigue model, and the lifespan is calculated by the inelastic energy dissipation. Based on Morrow fatigue model, $N_{\mathrm{f}}^{-0.69}$ is proportional to inelastic strain energy

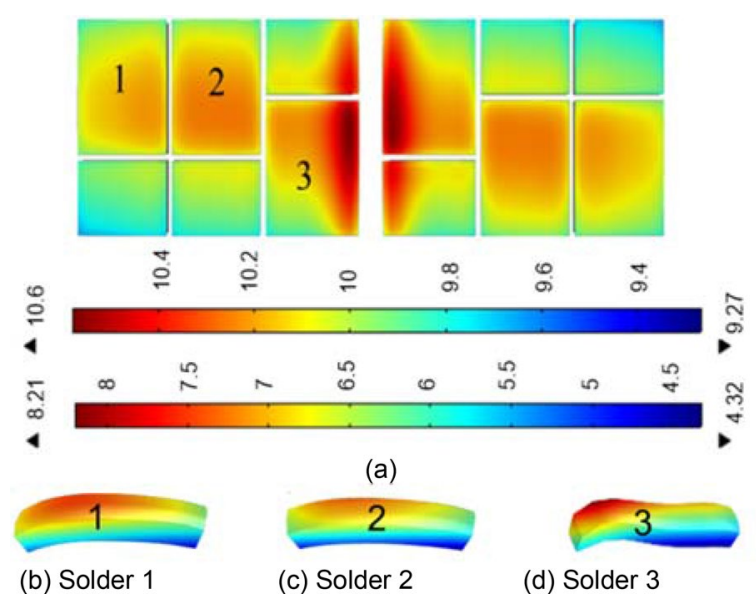

Fig. 8 Displacement distribution and deformation shape of $\mathrm{Sn}-3.5 \mathrm{Ag}$ solder layer: a displacement distribution of $\mathrm{Sn}-3.5 \mathrm{Ag}$ solder layer, top bar: IGBT with copper substrate $(\mu \mathrm{m})$, bottom bar: IGBT with vapour chamber substrate $(\mu \mathrm{m})$. b-d deformation shapes of solder 1 , solder 2 and solder 3 , respectively 


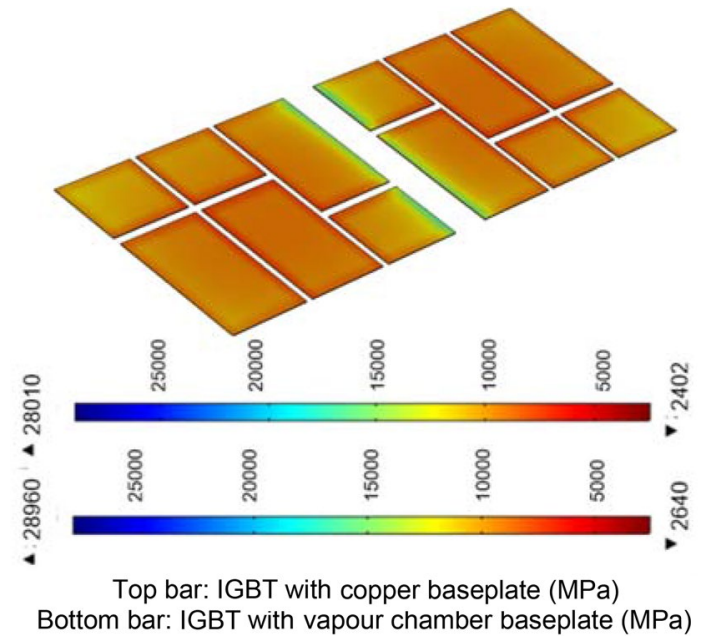

Fig. 9 Lifespan prediction of $\mathrm{Sn}-3.5 \mathrm{Ag}$ solder layer

density $\Delta W_{\text {in }}$. High junction temperature and low temperature uniformity normally cause large thermal strain and increase the thermal fatigue. As shown in Fig. 9, the weakest area is located at the edge of solder layer. In IGBT integrated with vapour chamber module, the simulated cycle number to failure is 2640 cycles on the $\mathrm{Sn}-3.5 \mathrm{Ag}$ solder layer. The cycles to failure increase by $9 \%$ compared with the IGBT with copper baseplate module.

\section{Conclusions}

This paper explores a new approach of direct cooling of IGBT power electronics integrated with vapour chamber. The purposes of the cooling concept are thermal resistance reduction and improve the reliability of power electronics. The cooling strategy has a highly integrated structure. The vapour chamber is directly soldered on the substrate. Tests and simulation are used to evaluate the performance of the cooling solution. The thermo-mechanical model contributes to a good understanding of failure mechanisms. The results lead to the following conclusions:

1. Temperature differences on the surface of copper and vapour chamber baseplate are 5.5 and $1.3{ }^{\circ} \mathrm{C}$ at heat input of $240 \mathrm{~W}$. This indicates that the vapour chamber has higher temperature uniformity than copper baseplate. IGBTs with vapour chamber modules reduce $45.2 \%$ of junction to ambient thermal resistance.

2. Simulation results show that the highest thermal stress is decreased by $21.8 \%$ compared with the copper baseplate case due to lower module temperature and uniformity temperature distribution.
3. The lifespan of the die solder joint is predicted. The cycles to failure increase by $9 \%$ compared with the IGBT with copper baseplate module.

Acknowledgements The authors would like to acknowledge the supports from EU H2020-MSCA-RISE project (Ref. 778104) of Smart thermal management of high power microprocessors using phasechange (ThermaSMART) and Innovate UK \& APC ACeDrive Project (Ref. 113167).

\section{Compliance with ethical standards}

Conflict of interest On behalf of all the authors, the corresponding author states that there is no conflict of interest.

Open Access This article is licensed under a Creative Commons Attribution 4.0 International License, which permits use, sharing, adaptation, distribution and reproduction in any medium or format, as long as you give appropriate credit to the original author(s) and the source, provide a link to the Creative Commons licence, and indicate if changes were made. The images or other third party material in this article are included in the article's Creative Commons licence, unless indicated otherwise in a credit line to the material. If material is not included in the article's Creative Commons licence and your intended use is not permitted by statutory regulation or exceeds the permitted use, you will need to obtain permission directly from the copyright holder. To view a copy of this licence, visit http://creativecommons.org/licenses/by/4.0/.

\section{References}

1. Mentor: Power cycling and thermal reliability of automotive IGBTS. Mentor Graphics Corporation, Wilsonville (2015)

2. Saums, D.: Vehicle electrification thermal management challenges and solutions overview. In: Proc. MEPTEC Therm. Manage. Workshop, San Jose, CA (2011)

3. Oh, H., Han, B., McCluskey, P., et al.: Physics-of-failure, condition monitoring, and prognostics of insulated gate bipolar transistor modules: a review. IEEE Trans. Power Electron. 30(5), 2413-2426 (2014)

4. Qian, C., Gheitaghy, A.M., Fan, J., et al.: Thermal management on IGBT power electronic devices and modules. IEEE Access 6 , 12868-12884 (2018)

5. Chen, X., Chen, G., Sakane, M.: Prediction of stress-strain relationship with an improved Anand constitutive model for lead-free solder Sn-35 Ag. IEEE Trans. Comp. Packag. Technol. 28(1), 111-116 (2005)

6. Bergman, T.L., Lavine, A., Incropera, F.P., et al.: Fundamentals of heat and mass transfer, pp. 533-534. Wiley, New York (2017)

7. Kandlikar, S.G., Hayner, C.N.: Liquid cooled cold plates for industrial high-power electronic devices - thermal design and manufacturing considerations. Heat Transfer Eng. 30(12), 918930 (2009)

8. Yin, S., Tseng, K.J., Zhao, J.: Design of AlN-based micro-channel heat sink in direct bond copper for power electronics packaging. Appl. Therm. Eng. 52(1), 120-129 (2013)

9. Stevanovic, L. D., Beaupre, R. A., Gowda, A. V., et al.: Integral micro-channel liquid cooling for power electronics. In: TwentyFifth Annual IEEE Applied Power Electronics Conference and Exposition (APEC) (pp. 1591-1597). IEEE, Palm Springs, CA (2010) 
10. Singh, R., Akbarzadeh, A., Mochizuki, M., et al.: Thermal characterization of copper micro-channel heat sink for power electronics cooling. J. Thermophys. Heat Transfer 23(2), 371-380 (2009)

11. Wu, R., Hong, T., Cheng, Q., Zou, H., Fan, Y., Luo, X.: Thermal modeling and comparative analysis of jet impingement liquid cooling for high power electronics. Int. J. Heat Mass Transf. 137, 42-51 (2019)

12. Whelan, B.P., Robinson, A.J.: Nozzle geometry effects in liquid jet array impingement. Appl. Therm. Eng. 29(11-12), 2211-2221 (2009)

13. Agbim, K.A., Pahinkar, D.G., Graham, S.: Integration of jet impingement cooling with direct bonded copper substrates for power electronics thermal management. IEEE Trans. Comp. Packag. Manuf. Technol. 9(2), 226-234 (2018)

14. Bhunia, A., Chen, C.L.: On the scalability of liquid microjet array impingement cooling for large area systems. J. Heat Transf. 133(6), 064501 (2011)

15. Connors, M.: Vapor chamber improves cooling of power semiconductors, power electronics technology. Ashington, Thermacore (2010)
16. Ltd, Fuji Electric Co.: Automotive IGBT module application note. Ohsaki, Fuji Electric Co Ltd (2015)

17. Wang, D., Yuan, Y., Luo, L.: Failure analysis of Sn-3.5 Ag solder joints for FCOB using 2-D FEA model. In: 11th international conference on electronic packaging technology and high density Packaging (pp. 624-629), IEEE (2010)

18. Xu, Z., Jiang, D., Li, M.: Si IGBT phase-leg module packaging and cooling design for operation at $200{ }^{\circ} \mathrm{C}$ in hybrid electrical vehicle applications.In: 2012 Twenty-seventh annual IEEE applied power electronics conference and exposition (APEC) (pp. 483-490). IEEE, Orlando, FL (2012)

19. Chen, Y., Li, B., Wang, X.: Investigation of heat transfer and thermal stresses of novel thermal management system integrated with vapour chamber for IGBT power module. Thermal Science and Engineering Progress 10, 73-81 (2019) 